\title{
Mudança linguística no modo imperativo - uma análise multissistêmica ${ }^{1}$
}

Henrique Santos Braga ${ }^{2}$

Resumo: A partir de um corpus composto por textos dramáticos, produzidos no sudeste brasileiro entre 1850 e 1975, nossa pesquisa se destina a estudar o uso que os falantes fizeram, ao longo desse período, das formas do singular do modo imperativo. Nosso intuito foi investigar usos de épocas passadas, visando a identificar se, ao longo do tempo, além da variação é possível ainda observar um processo de mudança linguística envolvendo essas formas verbais. Para tratar do fenômeno em questão, optamos pela Teoria multissistêmica ( $c$. Castilho, 2006) e ainda por sugestões metodológicas da sociolinguística variacionista para quantificar os dados em análise.

Palavras-chave: modo imperativo, variação e mudança linguística, formas de tratamento, polidez, teoria multissistêmica.

\begin{abstract}
From a corpus made up of dramatic texts produced in Brazil's southeast region between 1850 and 1975, our research aims to study speakers' usage of the imperative mood in the singular form during this period of time. Our intention was to investigate usage as it was at that time, aiming to discover whether or not it is still possible, in addition to variation, to observe a process of language change involving these verbal forms. To address this phenomenon, we have selected the multissystemic theory (cf. CASTILHO, 2006), quantifying the data according to variationist sociolinguistics.
\end{abstract}

Keywords: imperative mood, language variation, language change, forms of address, politeness, multissystemic theory.

Este artigo é resultante da dissertação de mestrado defendida pelo autor, "Desaparecimento da flexão verbal como marca de tratamento no modo imperativo - um caso de variação e mudança no Português Brasileiro".

2 Doutorando em Filologia e Língua Portuguesa pela Universidade de São Paulo (USP). Email: henriquecer@gmail.com. 


\section{Variação e mudança no modo imperativo}

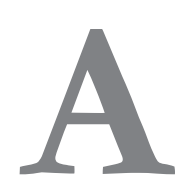

variação entre formas imperativas no Português Brasileiro (doravante PB) já está documentada há um tempo em estudos bem fundamentados sobre o tema ( $c f$. Faraco, 1986; Scherre, 1998; Lima-Hernandes \& Spaziani, 2002). Esses autores abordaram um descompasso entre a tradição gramatical e o uso efetivo dos falantes: apesar de a orientação normativa associar cada uma das formas a uma pessoa gramatical, não é exatamente isso o que se observa no uso dos falantes: em contextos de predominância do pronome de terceira pessoa "você", a forma tida como de segunda pessoa gramatical - a indicativa - é bastante recorrente. Inspirados nesses estudos, que abordaram sincronicamente o tema - analisando ocorrências do final do século XX -, resolvemos, porém, seguir outro caminho: investigamos usos de épocas anteriores - mais especificamente entre 1850 e 1975 -, buscando um momento histórico em que a descrição normativa do fenômeno tivesse lastro no uso efetivo dos falantes. Com isso, pudemos pontuar não só um incipiente processo de variação, mas também o surgimento de um processo de mudança linguística.

2. O corpus analisado - gêneros textuais e processos de mudança

Os diversos estudos sobre gêneros textuais deixam cada vez mais evidente que a escolha criteriosa do corpus é etapa fundamental na investigação linguística. Especialmente no caso do imperativo, constatamos como a ocorrência dessas formas verbais é grandemente favorecida ou dificultada em função do gênero discursivo.

Constatamos que as conversações do projeto NURC - SP, por exemplo, contêm uma baixíssima frequência de imperativos, certamente porque as condições de interação entre aqueles falantes não favorecem ordens, pedidos ou sugestões que sejam carreados pelas formas verbais em estudo. Também a busca em anúncios publicitários se mostrou infrutífera: consultando inúmeras propagandas em revistas de grande circulação, verificamos que tal gênero textual não favorece a variação das formas, pois nele é praticamente categórico o uso das formas imperativas oriundas do subjuntivo. À mesma conclusão chegaram Scherre et alii $(2000)^{3}$, quando dizem que "nos eventos de língua escrita de propaganda que não envolvem diálogo, a expressão do imperativo se faz predominantemente por meio da forma subjuntiva". Mesmo o corpus 
então disponível do Projeto Para História do Português Brasileiro (PHPB), no núcleo paulista, em que figuravam as "Cartas de leitores e cartas de redatores", apresentava ínfima incidência de formas imperativas - apenas 83 formas nas 177 cartas pesquisadas.

Nossa última e bem-sucedida tentativa foram textos teatrais. Elegemos peças de diferentes épocas, formando o quadro representado abaixo:

\begin{tabular}{|c|l|}
\hline Período & \multicolumn{1}{|c|}{ Peça } \\
\hline \multirow{2}{*}{$1^{\circ}$} & Orfeu na roça [1868] \\
\cline { 2 - 2 } & O tipo brasileiro [1872] \\
\hline \multirow{2}{*}{$2^{\circ}$} & O Caboclo [1886] \\
\cline { 2 - 2 } & A Capital Federal [1897] \\
\hline \multirow{2}{*}{$3^{\circ}$} & Que pena ser só ladrão... [1905] \\
\cline { 2 - 2 } & Terra natal [1920] \\
\hline \multirow{2}{*}{$4^{\circ}$} & O Patinho Torto (ou Os mistérios do sexo) [1924] \\
\cline { 2 - 2 } & O Rei da Vela [1937] \\
\hline \multirow{2}{*}{$5^{\circ}$} & Bonitinha, mas ordinária [1962] \\
\cline { 2 - 2 } & O abajur lilás [1969] \\
\hline
\end{tabular}

Tabela 1: períodos e peças analisadas

A diversidade de situações que o campo da ficção proporciona faz com que as formas imperativas sejam abundantes e, inclusive, com que possamos estabelecer variáveis extralinguísticas em função dessas diferentes situações. Além disso, não se pode ignorar que o teatro é um "reflexo da sociedade que lhe serve de berço", como afirma Braga (1999: 29)4.

Salientamos que, como o próprio gênero textual é fator de variação e como o a variação regional deve ser ponderada, limitamo-nos a tecer comen-

3 SCHERRE, M. M. P. et alii. "Restrições sintáticas e fonológicas na expressão variável do imperativo no português do Brasil”. II Congresso Nacional da ABRALIN e XIV Instituto Lingüístico. Florianópolis, Taciro - Produção de Cds Multimídia, 2000, pp.1333-1347.

4 BRAGA, C.M. Teatro brasileiro na República Velha - Reflexões sobre a dramaturgia brasileira (1889-1930). Tese de Doutoramento. ECA/USP, 1999. 
tários sobre o $\mathrm{PB}$ empregado em textos teatrais, produzidos na região sudeste brasileira ${ }^{5}$ entre 1850 e 1975. Mesmo assim, porém, acreditamos serem possíveis extrapolações a partir de nosso estudo.

3. Estratégias para surpreender o processo de mudança

Para surpreender um processo de mudança no uso do imperativo, dividimos nosso corpus em corpora menores, formando cinco períodos de 25 anos cada $^{6}$. Realizamos então, por meio do Goldvarb, leituras em separado, para cada um dos períodos que delimitamos. Com isso, pudemos perceber que, nos diferentes lapsos de tempo, os fatores tiveram diferentes comportamentos, evidenciados nos diferentes pesos relativos obtidos em cada época e que mesmo os fatores selecionados como relevantes e os descartados de cada período não foram exatamente os mesmos, pelo que defendemos estarmos diante de um processo de mudança linguística.

\section{Os fatores de variação em análise}

Além da metodologia laboviana, nossa análise sobre o fenômeno imperativo é pautada pela Teoria Multissistêmica (cf. Castilho, 2006) ${ }^{7}$, que, ao analisar o comportamentos dos elementos linguísticos, considera-os inseridos num sistema complexo, formado por subsistemas autônomos (o que implica negar relações determinísticas), e leva em conta ainda que tais elementos carregam traços correspondentes a cada um desses subsistemas.

Em face dessa orientação, como no cerne da questão do imperativo estão flexão verbal e relações interpessoais, demos destaque aos subsistemas mais relacionados a tais aspectos, respectivamente, o gramatical e o semântico-pragmático.

5 Temos consciência de que o rótulo "região sudeste" ainda pode ser um tanto abrangente, porém defendemos que a análise desse universo extenso serve como relevante ponto de partida para posteriores análises, mais detidas em variedades específicas.

6 A subdivisão dos períodos foi esta: a) 1850-1875; b) 1876- 1900; c) 1901-1925; d) 19261950; e) 1951-1975.

CASTILHO, A. T. Abordagem da língua como um sistema complexo. Contribuições para uma nova Lingüistica Histórica. Inédito, 2006. 
Dessa forma, no âmbito gramatical, avaliamos as seguintes variáveis independentes: tipo de tratamento ("tu", "você" ou "senhor(a)") ${ }^{8}$, preenchimento do sujeito, ordem do sujeito e posição do pronome átono.

No âmbito semântico-pragmático, baseamo-nos de modo geral em Scherre $(1998,2004)$ e Paredes Silva et alii $(2000)$, para quem o grau de formalidade interfere na escolha por uma ou outra das formas em variação. Partindo disso, pormenorizamos a noção de "formalidade", analisando diferentes marcas do fenômeno, tanto linguísticas quanto ou extralinguísticas. Detivemonos sobre os seguintes fatores: tipo de tratamento (saliente-se que a escolha por uma das formas pronominais, como demonstra Cintra $(1972)^{9}$, decorre do tipo de relação estabelecida pelos interlocutores), polaridade (considere-se que, culturalmente, a negação exige um maior nível de polidez), tipos de atos de fala, monitoramento por terceiros sobre a conversação, tipos de relação entre interlocutores, posição na hierarquia social.

Desses fatores, os selecionados em cada período foram os seguintes, nesta ordem de importância:

\begin{tabular}{|c|l|}
\hline Período & \multicolumn{1}{|c|}{ Fatores selecionados, em ordem de relevância } \\
\hline $1850-1875$ & $\begin{array}{l}\text { tipo de tratamento, tipo de relação entre interlocutores, } \\
\text { monitoramento da conversação }{ }^{10}\end{array}$ \\
\hline $1876-1900$ & $\begin{array}{l}\text { tipo de tratamento, polaridade e ordem de colocação dos } \\
\text { clíticos }\end{array}$ \\
\hline $1901-1925$ & $\begin{array}{l}\text { tipo de tratamento, polaridade e tipo de relação entre } \\
\text { interlocutores }\end{array}$ \\
\hline $1926-1950$ & tipo de tratamento e tipo de relação entre interlocutores \\
\hline $1951-1975$ & $\begin{array}{l}\text { tipo de relação entre interlocutores, tipo de ato de fala, } \\
\text { polaridade tipo de tratamento }\end{array}$ \\
\hline
\end{tabular}

Tabela 2: fatores selecionados em cada um dos períodos

8 A decisão por lidar com o tipo de tratamento enquanto fator gramatical deve-se ao fato de que se fazia necessário investigar até que ponto o pronome sujeito seria mesmo motivador de uma concordância verbal determinada pela tradição normativa, segundo a qual o pronome "tu" levaria à forma indicativa, tida como segunda pessoa do modo imperativo, e os pronomes "você" e "senhor" levariam à subjuntiva, tida como terceira pessoa.

9 CINTRA, L. L. Sobre 'formas de tratamento' da lingua portuguesa. Lisboa: Horizonte, 1972.

10 Com o fator monitoramento intentávamos averiguar se, em alguma medida, o fato de a conversa ser presenciada por terceiros acarretaria um maior respeito ao uso previsto pela norma. Contamos assim com a possibilidade de haver uma espécie de relação diretamente proporcional entre o número de participantes de uma interlocução e a preocupação em 
Como se vê, os fatores selecionados em cada período e sua ordem de importância não apresentam uniformidade, indicando que, na amostra do PB que compõe nosso corpus, as variáveis atuaram de modo distinto ao longo dos anos. Dada a finalidade e a extensão deste trabalho, porém, não discutiremos cada um dos períodos. Para dar destaque ao processo de mudança que se pode surpreender ao longo dos anos, privilegiando os resultados do quinto período, contrastando-os aos demais.

\subsection{Os fatores e a mudança}

Ao analisarmos períodos anteriores à contemporaneidade - na qual diferentes autores constataram a frequente associação entre formas imperativas do indicativo e pronome "você", combinação não prescrita pela tradição normativa - levantamos possíveis explicações para esse estágio atual, que nos parece configurar-se com mais clareza neste que denominamos em nosso estudo como quinto período, representado por ocorrências coletadas das peças "Bonitinha, mas ordinária"" e "O abajur lilás"12.

Já a seleção de fatores realizada pelo Gold Varb nos leva a entender que a relação entre forma pronominal e forma imperativa enfraqueceu-se ao longo dos anos, pois, em ordem de relevância, foram selecionados neste período tipo de relação entre interlocutores, tipo de ato de fala, polaridade e tipo de tratamento. Dessa maneira, o fator que havia sido selecionado como o mais relevante à variação nos quatro períodos anteriores, passa a ser, entre os selecionados, o de menor peso.

Contudo, por mais que segundo os dados do programa o tipo de tratamento seja o fator de menor relevância, para nós é justamente este o fator principal. Exatamente essa alteração nos aponta o processo de mudança no modo imperativo no PB, sobretudo no que diz respeito a um enfraquecimento da relação entre forma verbal e pronome sujeito.

respeitar-se a prescrição normativa. Como, porém, tal fator foi selecionado apenas nesse primeiro período e, doravante, iremos comparar os resultados das diferentes épocas, não vemos necessidade de nos deter na análise dessa variável, até mesmo porque o âmbito semântico-pragmático será bastante discutido a partir do tipo de relação entre interlocutores.

11 RODRIGUES, Nelson. Bonitinha, mas ordinária. São Paulo: Brasiliense, 1965 [1962].

12 MARCOS, Plínio. O abajur lilás. São Paulo: Global, 1975 [1969]. 
4.1.1. Fatores semântico-pragmáticos: "tipo de relação entre interlocutores”, "tipos de atos de fala" e "polaridade"

A seleção do tipo de relação entre interlocutores como o fator mais relevante neste período é um forte indicador de que a escolha da forma imperativa passa a se reger mais por aspectos semântico-pragmáticos que por aspectos gramaticais.

\begin{tabular}{|l|c|c|}
\hline & Indicativo & Subjuntivo \\
\hline pessoas desconbecidas ${ }^{13}$ & - & - \\
\hline pessoas apenas conbecidas & 0.20 & 0.80 \\
\hline familiares ou amigos & 0.69 & 0.31 \\
\hline de superior hierárquico a & 0.51 & 0.49 \\
\hline subordinado & & 0.50 \\
\hline $\begin{array}{l}\text { de subordinado a superior } \\
\text { bierárquico }\end{array}$ & 0.50 & \\
\hline
\end{tabular}

Tabela 3: tipos de relação entre interlocutores - probabilidades no quinto período

O tratamento de subordinado a superior, que aqui não privilegia nenhuma das formas imperativas, havia levado a uso categórico da forma subjuntiva em todos os períodos em que o tipo de relação entre interlocutores fora selecionado como estatisticamente relevante. Dessa maneira, o resultado 0.50 indica enfraquecimento do que fora um forte fator de restrição à mudança.

Pelos resultados das relações entre familiares ou amigos, defendemos que as formas indicativas se prestem mais às relações de menor cerimônia, já que tais formas apresentam 0.69 de probabilidade. Lidando, entretanto, com as outras duas relações de simetria, os resultados não permitem uma interpretação assim imediata: enquanto para a mais distante - entre pessoas desconbecidas temos uso categórico das formas indicativas do imperativo, para a mais próxima - entre pessoas apenas conhecidas - temos a maior probabilidade no período de surgirem formas subjuntivas (0.80). Diante disso, fica-nos uma questão: um possível rearranjo das propriedades semântico-pragmáticas, ainda incipiente nesse quinto período, teria como desdobramento uma espécie de instabilidade no sistema?

Sobre o fator tipo de ato de fala, sua seleção como relevante ter ocorrido apenas neste contexto do quinto período já é em si um dado de suma impor-

13 Entre pessoas desconhecidas, houve uso categórico da forma indicativa. 
tância para se reforçar a tese de que os fatores semântico-pragmáticos se tornam mais impactantes nesse processo, a ponto de um fator que jamais houvera sido selecionado como relevante passar a sê-lo.

Tratando em primeiro lugar das probabilidades relacionadas a cada tipo de ato de fala ${ }^{14}$, formulamos interpretações que possivelmente expliquem particularidades de diferentes usos das formas imperativas. Observemos:

\begin{tabular}{|l|c|c|}
\hline & Indicativo & Subjuntivo \\
\hline comando cordial & 0.49 & 0.51 \\
\hline comando rude & 0.56 & 0.44 \\
\hline pedido de desculpas ${ }^{15}$ & - & - \\
\hline Conselho & - & - \\
\hline Súplica & 0.12 & 0.88 \\
\hline Ofensa & 0.03 & 0.97 \\
\hline
\end{tabular}

Tabela 4: tipos de ato de fala - probabilidades no quinto período

Nos tipos de atos diretivos aqui denominados comando, notamos que, embora levemente, as propriedades concernentes à maior ou à menor polidez - respectivamente cordialidade e rudeza - interferem na seleção das formas imperativas. Observe-se que a cordialidade favorece a forma subjuntiva (0.51) e a rudeza, a indicativa (0.56).

Ao observar o uso categórico nos conselhos, porém, temos argumento mais forte para julgar as formas indicativas como as de proximidade: se na situação de aconselhamento não existe a imposição de um comando, de uma ordem, tem-se uma maior aproximação, uma maior intimidade entre os interlocutores. Justamente nesses contextos houve favorecimento à forma imperativa do indicativo.

Sobre as formas subjuntivas, razão considerável para defendermos que a propriedade da polidez esteja ativada nelas se deve ao fato de, na totalidade dos pedidos de desculpas, serem essas as formas encontradas. Também nas súplicas, ato de fala em que o traço da humildade é patente, as formas subjuntivas são outra vez bastante favorecidas (0.88).

14 Lembramos que a tipologia dos atos de fala utilizada neste trabalho está descrita na seção 1.2.2.2.1.

15 O programa não gerou probabilidades para pedido de desculpas nem para conselho, pois os dois fatores levaram a uso categórico, respectivamente, das formas do subjuntivo e do indicativo. 
As ofensas, por sua vez, parecem destoar da análise que fazemos. Isso porque, se defendemos que os comandos rudes desfavorecem as formas subjuntivas, por neles ser dispensado o tratamento cerimonioso, o mesmo, a princípio, dar-se-ia com as esse tipo de ato de fala. No entanto, no caso das ofensas, a maior probabilidade é de surgirem formas subjuntivas (0.97). A despeito disso, por ora, destacamos que os casos de comando rude são mais representativos no período (118/314) do que os casos de ofensa (4/314).

Sobre o fator polaridade, acrescentamos que, embora as sentenças positivas não atuem fortemente na variação, nas sentenças negativas é considerável a probabilidade de ocorrer uma forma subjuntiva (0.79), o que atribuímos a uma maior necessidade de polidez nesse tipo de situação.

\begin{tabular}{|l|c|c|}
\hline & Indicativo & Subjuntivo \\
\hline polaridade positiva & 0.53 & 0.47 \\
\hline polaridade negativa & 0.41 & 0.79 \\
\hline
\end{tabular}

Tabela 5: polaridade da sentença e formas imperativas - quinto período

\subsubsection{O fator "tipo de tratamento"}

Ao relacionar o pronome sujeito a escolha da forma verbal, destaquese que, embora neste quinto período tenhamos uma considerável frequência do pronome "tu" (45,1\%), praticamente todas as ocorrências (138/139) estão na peça "O abajur lilás", de Plínio Marcos; ao mesmo tempo, todas as ocorrências de "você" (166/166) e "senhor" (3/3) estão na peça "Bonitinha, mas ordinária". Sobre "O abajur lilás", é importante dizer que escolhemos tal obra para que, neste quinto período, tivéssemos uma espécie de "grupo controle" nas nossas estatísticas: como no período em questão o tratamento por "você" é quase categórico na maioria das peças produzidas na região sudeste, espaço que delimitamos para esta pesquisa, buscamos essa obra na qual é o tratamento por "tu" que se dá de modo categórico.

Observe-se que os personagens de "O abajur lilás" são representativos de uma variedade - inclusive mencionada por Paredes Silva et alii (2000) própria de grupos sociais marginalizados que praticam um uso não padrão de "tu" - registrado pelas autoras, primeiramente, em peças dos anos 50 . Vejamos exemplos: 
(1) Dilma - Tu que pensa. A bichona bota a boca no trombone e tu se entralha. Nenhuma cafetina te aceita. Elas ficam achando que tu é de criar caso. O que tu pensa? Essa raça maldita é toda combinada. Uma cafetina dá cobertura pra outra. E com essas e outras, a gente é que se entruta. (J: 25)

(2) Célia - Eu sei, eu sei, tu tem filho. É legal. Tá certo. Mas é por ele. Por ele, tu deve embracar na minha. (J: 26)

(3) Giro - Amanhã eu troco. Se tu se virar bem hoje. (J: 47)

Célia e Dilma são prostitutas, Giro é aliciador. Esses personagens, todos marginalizados, fazem uso do pronome "tu" sem que isso acarrete consequências na concordância verbal mesmo no modo indicativo, conforme vemos nos exemplos. Provavelmente, portanto, o mesmo acontece no modo imperativo: certamente não parece ser devida ao pronome " $t u$ " a presença das formas imperativas indicativas. Por esse motivo é coerente afirmar que, nesse contexto, não se podem correlacionar os fatores tipo de tratamento e tipo de relação entre interlocutores, afinal, o uso de "tu" ou "você" passa a ser imposto ao falante mais pela sua variedade linguística do que por um intuito de distinguir diferentes níveis de cerimônia.

Dito de outro modo, reduzem-se as propriedades semântico-pragmáticas que, ativadas no pronome, participam da escolha por uma das formas imperativas. Além disso, nota-se também uma redução na interferência que a marca gramatical de pessoa presente no pronome teria sobre a seleção feita pelo falante entre uma das formas verbais imperativas. Os cálculos probabilísticos evidenciam isso:

\begin{tabular}{|l|c|c|c|c|c|c|c|c|c|c|}
\hline & \multicolumn{3}{|l|}{$1^{\circ}$ período } & \multicolumn{2}{l|}{$2^{\circ}$ período } & \multicolumn{2}{l|}{$3^{\circ}$ período } & \multicolumn{2}{l|}{$4^{\circ}$ período } & \multicolumn{2}{l|}{$5^{\circ}$ período } \\
\hline & $I N D$ & SUB & IND & SUB & IND & SUB & IND & SUB & IND & SUB \\
\hline TU & 0.98 & 0.02 & 0.98 & 0.02 & 0.95 & 0.05 & 0.99 & 0.01 & 0.63 & 0.37 \\
\hline VOCÊ & 0.36 & 0.64 & 0.04 & 0.96 & 0.31 & 0.69 & 0.39 & 0.61 & 0.40 & 0.60 \\
\hline SENHOR & 0.01 & 0.99 & 0.01 & 0.99 & 0.0 & 1 & 0.12 & 0.88 & 0.06 & 0.94 \\
\hline
\end{tabular}

Tabela 21: tipo de tratamento - probabilidades nos quarto primeiros períodos

Considerando as chances de, estabelecendo-se um tratamento por "tu", ser utilizada uma forma imperativa do indicativo, temos nos quatro primeiro períodos probabilidades que se aproximam de um uso categórico. No quinto período, porém, em que $87 \%$ das formas são indicativas, temos uma probabilidade de apenas 0.63 . 
Quanto ao pronome "você", embora em termos probabilísticos continue havendo uma maior possibilidade de as formas subjuntivas associarem-se a ele, no período em questão encontramos a menor dessas probabilidades: 0.60 .

Sobre o uso de "senhor", sua relação com as formas subjuntivas atinge 0.94. Embora tal pronome tenha sido pouco frequente neste quinto, estando em apenas 1\% (3/308) das ocorrências imperativas, não se deve descartar a possibilidade de que justamente por ser um evidente marcador de polidez ao contrário do que passou a ocorrer na distinção "tu"/"você" - tal pronome siga atrelado ao uso da forma subjuntiva.

Os resultados sobre os usos de "tu" e de "você", por sua vez, reforçam a tese de que ocorre um enfraquecimento da concordância verbal entre pronome sujeito e forma imperativa, tornando-se assim o subsistema gramatical menos ativo na escolha por uma ou outra forma imperativa.

\section{Conclusões}

Investigando o comportamento das formas imperativas entre $1850 \mathrm{e}$ 1975 , ponderamos que, se diferentes autores perceberam em variedades contemporâneas um descompasso entre a forma imperativa e o pronome sujeito, isso se deve a um processo de mudança linguística pelo qual as propriedades semântico-pragmáticas dos pronomes foram substancialmente alteradas, não tendo ocorrido o mesmo com as propriedades das formas verbais. Se a marcação de [+-proximidade/ distanciamento] passa por uma desativação nos pronomes "tu" e "você", nada indica acontecer o mesmo nas formas imperativas e, desse modo, os falantes passam a selecionar a forma do indicativo ou a do subjuntivo considerando em primeiro lugar aspectos semântico-pragmáticos, não aspectos gramaticais.

Referências bibliográficas

ANDRADE, Oswald de (1996 [1931]). O Rei da Vela. São Paulo: Globo.

AZEVEDO, Aluísio (2002). "O Caboclo”. In: FARIA, João Roberto. Teatro de Aluísio Aževedo e Emílio Rouède. São Paulo: Martins Fontes, pp. 159-277.

AZEVEDO, Arthur de (1965 [1897]). A Capital Federal. Rio de Janeiro: Letras e Artes.

BRAGA, C.M (1999). Teatro brasileiro na República Velha - Reflexões sobre a dramaturgia brasileira (1889-1930). Tese de Doutoramento. ECA/USP. 
BRAGA, Henrique Santos (2008). Desaparecimento da flexão verbal como marca de tratamento no Modo Imperativo - Um caso de variação e mudança no Português Brasileiro. Dissetação de mestrado. FFLCH/USP.

CASTILHO, Ataliba Teixeira (2006). Abordagem da lingua como um sistema complexo. Contribuiçöes para uma nova Lingüística Histórica. Inédito.

CINTRA, L. L (1972). Sobre "formas de tratamento" da lingua portuguesa. Lisboa: Horizonte.

COELHO NETTO, Henrique Maximiano (1973 [1931]). O Patinho Torto on Os mistérios do sexo. Rio de Janeiro: Serviço Nacional de Teatro, Ministério da Educação e Cultura.

FARACO, Carlos Alberto (1986). "Considerações sobre a sentença imperativa no Português do Brasil". In: DELTA, vol. 2, n 1, pp. 1-15.

FRANÇA JÚNIOR, Joaquim José da (1980 [1872]). “O tipo brasileiro”. In: O teatro de França Júnior. Rio de Janeiro: Serviço Nacional de Teatro, Ministério da Educação e Cultura, Funarte, pp. 135-155.

LABOV, Willian (1989). Sociolingüistic Patterns. Philadelfia: University of Pennsylvania Press, 1972, apud. SILVA-CORVALÁN, C. Sociolingüística. Teoriay Análisis. Madrid: Editorial Alhambra. . (1994), Principles of Linguistic Change - Internal Factors. Cambridge: Blackwell Publixhers.

LIMA-HERNADES, Maria Célia \& SPAZIANI, Lídia (2002). Modo imperativo em cartas brasileiras: um caso de variação. (Trabalho apresentado no XIII Congresso da ALFAL - São José da Costa Rica).

MARCOS, Plínio (1975 [1969]). O abajur lilás. São Paulo: Global.

PAREDES SILVA, V. L. et alii (2000). "Variação na 2a pessoa: o pronome sujeito e a forma do imperativo". In: Gragoatá, 9, 115-123. Niterói: EdUFF.

RIO, João do (2002 [1905]). “Que pena ser só ladrão...”. In: Teatro de João do Rio. São Paulo: Martins Fontes, pp. 173-206.

RODRIGUES, Nelson (1965 [ 1962]). Bonitinha, mas ordinária. São Paulo: Brasiliense.

SCHERRE, M. M. P. et alli (1998). "Phonic Paralelism: Evidence from the Imperative Form in Brazilian Portuguese”. In: PARADIS, C., VICENT, D., DESHAIES, D., LAFOREST, M. (eds). Papers in Sociolinguistics. Quebec: Éditions Notable, pp. 63-72.

. (2000). Restrições sintáticas e fonológicas na expressão variável do imperativo no português do Brasil. II Congresso Nacional da ABRALIN e XIV Instituto Lingüístico. Florianópolis, Taciro - Produção de Cds Multimídia, pp.1333-1347.

. (2004). "Norma e uso - o imperativo no português brasileiro". In: DIETRICH, W. \& NOLL, V. (Orgs.) O Português do Brasil- Perspectivas da pesquisa atual. Lingüística lusobrasileira, Vervuert / Iberoamericana. pp. 231-260.

VASQUES, Francisco Correa (1979 [1868]). “Orfeu na roça”. In: FERREIRA, Procópio. O ator Vasques. Rio de Janeiro: Ministério da Educação e Cultura, Seac, Funarte, Serviço Nacional de Teatro, pp. 166-210.

VIANNA, Oduvaldo (2003). “Terra Natal”. In: MADEIRA, Wagner Martins. Formas de teatro de comédia: a obra de Oduvaldo Vianna. Doutorado (FFLCH), pp. 491-522.

WEINREICH, U, LABOV, W. \& HERZOG, M (2006 [1968]). Fundamentos empíricos para uma teoria da mudança lingüística. Trad. BAGNO, M. São Paulo: Parábola Editorial.

Recebido em: 05/dez./2010

Aprovado em: 05/mai./2011 